\title{
Impacts of an Integrated Information Center on Faculty End-Users: A Qualitative Assessment
}

\author{
Diane Lending \\ School of Management, University of Michigan-Dearborn, Dearborn, MI 48128. \\ E-mail: dlending@fob-f1.umd.umich.edu \\ Detmar W. Straub \\ Computer Information Systems, College of Business Administration, Georgia State University, \\ Atlanta, GA 30302. E-mail: dstraub@gsu.edu
}

\begin{abstract}
This article describes an ethnographic study of a selected group of faculty end-users; the purpose of this qualitative assessment was to triangulate on several phenomena under investigation to better understand the impacts of the Integrated Information Center (IIC) on end-user work behaviors.
\end{abstract}

If managers wish to control, guide, and encourage the use of new information technologies (IT), they need to understand the decision-making processes of their employees - the individual knowledge workers who have a high information content in their work inputs and outputs (Davis, Collins, Eierman, \& Nance, 1993). Specifically, they are going to need insight about why and how knowledge workers choose to use, or not to use, various technologies. Only by coming to an awareness of this individual adoption process can managers plan training and orientation programs and personally direct the exploitation of these expensive and sophisticated tools.

The Technology-to-Performance Chain model (see Goodhue, 1997) provided the underlying theoretical model for the research reported herein. This model proposes that when an individual decides to use a technology on a task, he or she first recognizes a fit between the technology, individual, and the task. The model also predicts that social norms, habit, and facilitating conditions influence the decision to use technology.

As informative as it is, the model leaves unanswered the question of when each of these factors comes into play. In other words, how can we explain when one of these conditions supersedes the others in the adoption decision of end-users? If habitual use inclines an individual to continue using a given technology, but fit-to-task

(C) 1997 John Wiley \& Sons, Inc. suggests switching to a different technology, which will finally dominate? Can we explain such choices when conditions in the workplace vary so widely across persons, settings, and times?

To answer such crucial questions, even preliminarily, and to attempt to explain how and why people use certain technologies, the present research employed the qualitative technique of ethnographic interviews. This methodology was able to probe more deeply into motives and explanations of behavior and individual decisions on technology adoption. It also allowed us to corroborate or confute the Technology-to-Performance Chain model, and, possibly, infer if and where the model might be incomplete. Furthermore, analysis of the interviews could provide a rich picture of the impacts of an Integrated Information Center (IIC).

\section{Interview Participants}

Interviews with selected faculty were conducted at two points during the period in which the IIC was being initiated and deployed in the organization. These interviews captured detailed descriptions of particular academic tasks, the use of technology for those tasks, the fit of technology, and the possible influence of that fit, or lack of fit, on technology choice.

Two waves of interviews were conducted, with some participating in both sets of interviews. The first wave occurred in the early stages of the implementation of the IIC; the second wave occurred after the IIC had been in operation over a year.

In the first wave of interviews, a categorization process advanced by Eisenhardt (1989) was used instead of a random selection process. Interviewees were chosen to maximize differences so that the extremes would be cov- 
TABLE 1. Methods of literature search.

1. Your personal collection of literature or reference lists from already acquired relevant literature

2. Information from your colleagues on possibly relevant citations via conversation, E-mail, telephone, or conferences

3 . Use of graduate assistants to find relevant citations

4. Browsing open library shelves

5. Reference books or fiche containing indexes for noncomputerized literature searches (e.g., Social Sciences Citation Index)

6. Online library catalogs of University holdings (e.g., LUMINA)

7. Electronic databases for literature searches of article abstracts or citations (e.g., ABI/INFORM)

8. Specialized services which provide you with copies of tables of content from pre-selected journals

9. Specialized services which provide you with abstracts on articles from pre-selected journals or on pre-selected topics

10. Other

ered and theory building facilitated (Eisenhardt, 1989). The necessary condition for inclusion in the sample was that interviewees were active researchers. Representativeness across professorial ranks was another condition, as was their completion of the general survey of faculty responses to new information technologies [ see Goodhue, Littlefield, \& Straub (1997), in this issue, for a discussion of the results of this survey]. To get the extremes, this survey was used to choose researchers who used maximally different research methods and used maximally different tools in their research.

Since participants were drawn from a faculty group about whom we had demographic and other psychometric information, the "general survey" condition for inclusion in the ethnographic interviews allowed us to statistically compare this subgroup to the faculty as a whole. Participants were chosen from the subset of the population who had completed the survey and were selected to maximize the diversity of faculty rank, type of research, assessment of fit of technologies, use of technologies, and assessment of the complexity of the technology. In the first wave of interviews, seven faculty members were chosen to be interviewed.

Thus, despite the fact that the categorization of participants was designed to maximize diversity, interviewees were not different from the rest of the faculty who responded to the survey. A straightforward series of $\mathrm{T}$ tests confirmed that the two groups were similar in the dimensions of technology use.

Participants in the second wave of interviews included five of the seven participants who were interviewed initially and agreed to be interviewed again. An additional 15 participants were chosen randomly from faculty who had responded to the second wave of the survey for a total of 20 interviews.

\section{Interview Schedule}

Interviews concentrated on the set of technologies used in searching for literature sources for research. This focus narrowed the scope of the study to an arena in which the IIC was expected to offer new methods for carrying out research. The interviews started in an unstructured vein, allowing as much unprompted explanation as possible, and then proceeded to a set of semi-structured questions. Each interview was conducted individually by one or two interviewers and took an average of 45 minutes to complete. The interviews were taped and transcribed for later detailed analysis.

The interview script or schedule called for an opening question in which the participant described a specific, active research project that required the deployment of literature search methods. Anchoring on a specific project allowed the participants to respond more easily and accurately to the questions. Next, participants were asked to describe the literature search methods used on the project.

After this unstructured discussion of literature search methods, participants were given a list of 10 literature search methods ( see Table 1). For each method, the questions listed in Table 2 were asked. These questions were designed to probe for unexpected rather than expected explanations which could be readily queried in the written questionnaire. Nevertheless, three expected explanations for use/non-use were built into the interview: (1) Social influence on use, (2) typicality of the research project, and (3) the participant's own innovativeness. Participants were queried directly about social influences and project

TABLE 2. Questions about specific method.

1. Did you use [this method] on the project we've been discussing?

If used:

a. Can you give me more details?

b. Is this a typical method of literature search for you? If not, is this the first time you've used this method? What prompted you to use it this time?

Had you considered using it before and not used it? Why?

c. Under what circumstances do you use this method?

d. Are there any outside influences such as your colleagues or the department that encourage or discourage your use of this method?

e. Do your colleagues use this method? Why or why not?

f. Thinking back to your first use of this method, did you know of anyone else using the method? What influenced this first use?

If not used:

a. Have you heard of this method? If not, go to next method.

b. Have you ever tried this method?

If yes, why did you try it? Why did you not use it on this project?

If no, have you ever considered using it? Why or why not? Are there outside influences such as your colleagues or the department that have influenced this choice?

c. Do your colleagues use this method?

If yes, discuss why you think they use it

Have you received any suggestion or encouragement to use it too?

2. How important do you consider [this method] for your research? 
TABLE 3. Coding scheme.

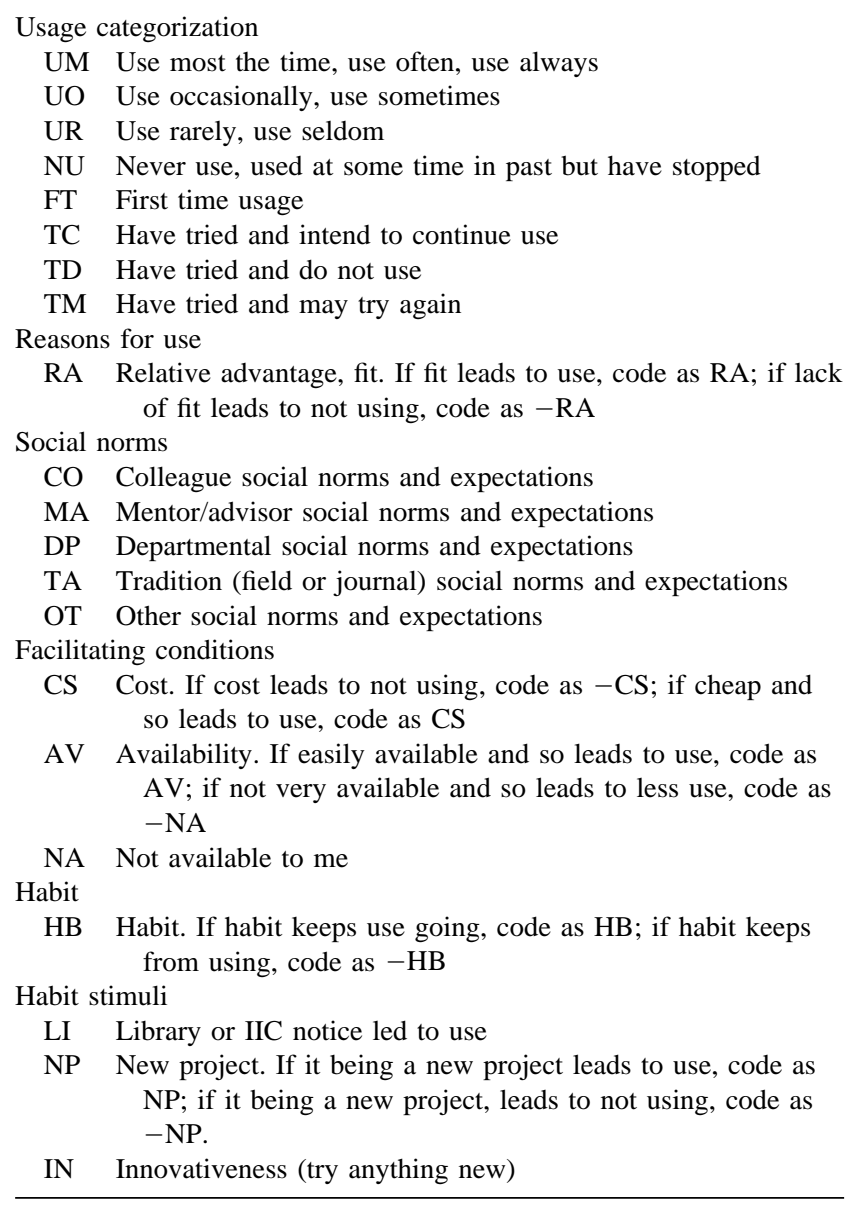

typicality. For innovativeness, each participant responded to a 10-item validated scale (based on Karahanna, 1993 ) assessing his or her level of innovativeness. The interview concluded with a discussion of the computer technologies available to participants.

\section{Field Notes and Coding Procedure}

Complementary ethnographic methods were used to analyze the interviews. First, each interviewer carefully considered the impression gained from the interview and, based on field notes and reminiscence, wrote a summary of these impressions. Second, a coding scheme was developed to more systematically analyze the data. Each interview was coded per the description below, and the coding analyzed as discussed in the next section. This coding scheme enabled the researchers to examine multiple (and competing) theoretical explanations for use and non-use.

\section{Coding}

Each interview transcript was divided into 14 sections: The introduction, the description of the research project, a general discussion of literature search methods, a section for each of the 10 specific methods, and the closing discussion.

Each of the literature search sections was classified by amount of use (see Table 3 for codes used to classify use). Particular reasons given for using, or not using, a method were coded according to the scheme delineated in Table 3. If a participant's reason was accompanied by an inclination towards increased use, the reason code was marked as positive. In the case of decreased use, the "reason', code was marked as negative. Codings were summarized for each participant in a tabular format, as exemplified in Table 4.

\section{Observations}

Results were analyzed across participants by counting how many times a reason for using, or not using, a technology was mentioned by the participants. Since there were 27 interviews and nine technologies, there were opportunities for 243 observations of reasons to use or not use a technology.

\section{Interpretation of Results}

The Technology-to-Performance Chain model (Goodhue, 1997) received significant support in our analysis of the qualitative data. The fit construct was overwhelmingly the most important factor in explaining initial use across technologies. Facilitating conditions take on a secondary, but still important role.

What also emerged in the qualitative assessment was that some faculty do not engage in continuous evaluation of the technologies present in their environment, but rather incline to habitual patterns of persistent use. In a dynamic representation of real-world circumstances, many of the causal agents in the model may determine habit as well as utilization.

Moreover, there seem to be certain triggering mechanisms (or agents) that result in breaking habits (persistent use) and reevaluating technologies for initial use. A heightened awareness of new technology serves this function, as does the launching of new research projects. Serendipitous events may also play a role in how new technologies come to be adopted. Table 5 summarizes the reasons given by participants for using, or not using, a technology.

\section{Evidence Related to Model Relationships}

In analyzing the interviews, we looked for evidence for, or against, the model concepts of fit, social norms, habit, and facilitating conditions. This evidence is discussed in the following sections.

Fit

In the vast majority of cases, interviewees indicated that they considered task-technology fit in determining 
TABLE 4. Coding example.

\begin{tabular}{llll}
\hline \multicolumn{1}{c}{ Method } & Use? & Why? & Comments* \\
\hline Personal Collection (PC) & UM & & \\
Info from colleague (IN) & UM & RA & \\
Graduate students (GR) & UO & & \\
Browsing shelves (BR) & UM & RA & \\
Index (book) (IB) & UO & RA & \\
Online catalog LUMINA (LU) & UM & RA & \\
Electronic search (ES) & NU & AV & \\
& & & $\begin{array}{c}\text { Fifteen years ago, the library } \\
\text { did not have-have not } \\
\text { checked since }\end{array}$ \\
Tables of Content (TC) & NU & - HB & \\
Abstracts (AB) & UM & DP & \\
Other-FirstSearch (OT/F) & UO & RA & First time used was to settle \\
& & & $\begin{array}{l}\text { a bet }- \text { has used ever } \\
\text { since }\end{array}$ \\
\hline
\end{tabular}

* He is very driven by habit. Once he gets into habits, he does not seem to question his methods at all.

whether or not to utilize a new technology. Table 5 makes it clear how often interviewees noted that fit was a significant determinant of use.

The interviews indicate, moreover, that participants asked themselves two even more basic questions when they developed a "fit" argument for their technology choices. First of all, they asked themselves if a given technology allowed them to accomplish the task. They next asked whether that technology was the best technology for that particular task. Since participants were being asked about multiple technologies that could perform the same task, the second question was clearly the more profound of the two.

The strong impression formed by the data in Table 5 was further reinforced by statements in the interviews themselves in which individuals indicated that they, indeed, did match technology to the requirements of the task at hand and chose the technology that suited the

TABLE 5. Percentage of times reasons were mentioned.

\begin{tabular}{lc}
\hline Reasons for use & $\begin{array}{c}\text { Percentage of time } \\
\text { mentioned* }\end{array}$ \\
\hline Fit & 82.8 \\
Social norms & 7.1 \\
Facilitating conditions & \\
Availability & 16.7 \\
Cost & 5.1 \\
Habit & 10.1 \\
\hline
\end{tabular}

\footnotetext{
* Percentages are of the total number of times that a reason could have been mentioned. Total number $=$ number of technologies $\times$ number of subjects. Number of feasible reasons $=243$.
}

situation. For example, when one participant was asked if he browsed library shelves, the following dialogue ensued:

Participant: "No, it's a waste of time."

Interviewer: "Why? Did you never find anything?"

Participant: "Or it's too much [to scan]. A lot of the database searches now give you abstracts so you scan [just] the abstracts and you will get hundreds and hundreds of articles and you will only find 10 or 20 that you really want to look at. It's much more efficient to do that via database searching abstracts than to go looking around the library. . . . I would use the open library shelves for looking in new areas.',

Similarly, another participant was asked why using his personal collection of literature was his typical method of literature search. His reply shows his inclination to match the technology to the task at hand:

I guess because I know most of the literature that's relevant. I have on occasion done big searches, but you don't find a whole lot. I have done [electronic] searches in areas I didn't know anything about, but in this I knew most of what I was doing so I didn't need to do that. When I move into a new area I do that. That's incredibly efficient.

As can be seen from these remarks, these participants are well aware of the alternative methods available to them. While realizing that they could do the same type of search with two different methods, one clearly has an advantage over the other in their perceptions. They also 
seem to believe that in different circumstances, the relative advantage of the two methods might be reversed.

\section{Social Norms}

One of the surprises from the interviews was how little faculty were influenced by social norms. The usual response to whether their colleagues used a manual or computer-supported technology was "I don't know." When asked about outside influences on such colleagues or department, they typically said there were none. In fact, if participants did believe that there were departmental norms, they felt no obligation to conform to these norms. For example, after one participant replied that he did not use electronic searches at all and never considered using them, he said: "Here in [my department], we are really in the computer age. The thought of going through and looking for a book mechanically by hand nowadays really is bizarre for this group." When asked if colleagues influenced his choice of technologies, another participant replied:

There's no question of outside influences. It depends on the phenomenon that is being studied. I mean, if it's a research project, it calls for certain kinds of searches. You do that search. Nobody can force me or not force me to do anything to do [with] how I conduct that search.

References to social norms that did surface tended to imply norms within the field. For example, one participant, describing how thorough his literature searches needed to be, went on to say:

See, the way I do my research, I don't go exhaustively for every possible reference. . . . My papers usually [have] much shorter reference lists than you would find typically in social psychology or organizational behavior. . . . I particularly send to economics . . . journals. And the tradition there is not to have very long laundry lists of references.

One explanation for why there was less than expected support for social norms as it relates to technology utilization is that faculty are quintessential knowledge workers in almost all respects, that is, knowledge and information are integral to nearly all of their inputs, processes, and outputs. This disposition to knowledge gathering/creating and rational discourse may lead to highly rational decisions about technology use.

Furthermore, the participant group here is largely autonomous with individual offices in which technology use or non-use is invisible from the outside. Department heads, moreover, are much less concerned about the means by which faculty carry out and publish research than they are in performance. In short, researchers are being judged, hypothetically at least, not on computer literacy or innovativeness in adopting new technologies, but on research productivity. Under such circumstances,

\section{Facilitating Conditions}

Facilitating conditions were also significant determinants of use. Two aspects of facilitation, accessibility and cost, will be explored.

Consistent with Culnan $(1984,1985)$ and others, accessibility of technology had a clear impact on participants' proclivities to use technology. Technologies that were available in the respondents' offices were used much more frequently than technologies that had to be sought out in other locations. This was true even when the remote technology had substantially more capabilities than the readily accessible desktop technology. A typical remark was: "Well, the fact that I can get right into it from my PC relatively easily, and the fact that I can just hit print screen. That encourages [my use of the technology.]"

The second aspect of facilitating conditions is cost. Perhaps as a function of the university environment, where faculty and students are not as fully aware of budget constraints as in a for-profit organization, cost was mentioned much less frequently. A typical remark was: "If I really knew I needed something from somewhere, cost wouldn't matter at all."

\section{Habit}

Finally, the qualitative data implies that habit is associated with persistent use. There was some evidence that even when the respondent was aware that an alternative technology existed, which might offer a better fit than the method currently used, the effort to try the new technology and evaluate it for adoption was too time-consuming. Accordingly, the respondent typically continued in habitual use of a possibly sub-optimal technology. A specific mention of habit was:

I mean part of the way I behave is just sort of habitual. I mean it's sort of how I used to do it in days when the libraries weren't quite as involved. And so some of that carries over in the sense that old habits are hard to break.

These participants knew that the method they were using was often not the best and also knew that other and better methods existed. The time to learn new methods was frequently given as the reason for persevering with less efficient methods. One participant describing why he did not use a specific index said:

And so I just physically pulled each copy of a journal and went through the bibliographies to see whether they had mention of his work. You know, it was very inefficient, and it took an hour or so. Whereas I'm quite sure that a citation index would have been more [efficient]. 
Another participant makes this same point:

I'd have my secretary . . . do it. Now I'd like to learn Lumina [the on-line library system], and I'd like to learn how to do it. But again it's a question of if I have the time to do it.

Conquering habitual inertia took various forms. For the most innovative participants, awareness of a new technology was enough to get them to try the technology. This awareness typically came through a library notice or the appearance of an option on their network menu. One participant who scored high on the innovativeness scale, when asked why she had tried using a particular method that was very new, responded:

Well, I logged into Lumina. And I think we got some little notice saying this thing had started out. And I just went in one day and I started looking at all these things. Just, I mean, the first time I searched it, I wasn't looking for anything. I was just fooling around.

For many participants, awareness was not enough, however. The stimulus for trying new technologies had to be tied to pursuit of research in a new area or to fortuitous events. One participant used a technologythat had been available for years on his desktop computer-for the first time when he needed to help his young son use the University library for a school project. Once he had used the technology and discovered how useful it was, he started using it for all of his literature searches.

\section{Implications of the Qualitative Analysis}

Qualitative data analysis reinforces the results of the quantitative data analysis (Goodhue et al., 1997), with some interesting and conceivably very significant differences. First of all, many of the variables in the research model, such as fit and facilitating conditions, were found to be important in this triangulation on interviewees' underlying evaluative processes. Social norms were found to have conspicuously little impact, to our surprise.

Given these results, managers would be advised to provide users with information about the usefulness of technologies for particular tasks. In showing users where task-technology fits exist, managers can encourage adoption in many cases. In this sample of university researchers, it is unclear as to whether attempts to strengthen social norms in favor of particular technologies would lead to increased use. But making the technologies easily accessible should lead to higher utilization.
Findings dealing with the effects of habit on persistent use and the way habits can be broken are particularly enlightening. Change agents need to consider how to effectively utilize triggers for change. These agents need to be aware that change is most likely to occur when users are ready for change, that is, when they encounter "novel situations and when new problems arise in old situations", (Ronis, Yates, \& Kirscht, 1989, p. 223). By making users keenly aware of the benefits of new technologies, for example, change agents can assist users when they are ready to break old habits. The best way to accomplish this overall goal is through a highly supportive environment in which users have ready access to information about the availability of a certain technology, its important features, and its usefulness for important tasks that the users frequently engage in.

Specifically, change agents should be prepared to provide both proactive and reactive information. First, regular and effective communications about technological innovations will serve as a trigger for some users. Other users, who for one reason or another are more resistant to change, will need information on-demand about available services when users have been influenced by external factors.

\section{References}

Culnan, M. J. (1984). The dimensions of accessibility to online information: Implications for implementing office information systems. ACM Transactions on Office Information Systems, 2, 141-150.

Culnan, M. J. (1985). The dimensions of perceived accessibility to information: Implications for the delivery of information systems and services. Journal of the American Society for Information Science, 36, 302-308.

Davis, G. B., Collins, R. W., Eierman, M. A., \& Nance, W. D. (1993). Productivity for information technology investment in knowledge workers. In: R. D. Banker, R. J. Kauffman, \& M. A. Mahmood (Eds.), Strategic information technology management perspectives on organizational growth and competitive advantage. Harrisburg, PA: Idea Publishing.

Eisenhardt, K. M. (1989). Building theories from case study research. Academy of Management Review, 14, 532-550.

Goodhue, D. L. (1997). The model underlying the measurement of the impacts of the IIC on the end-users. Journal of the American Society for Information Science, 48, 449-453.

Goodhue, D. L., Littlefield, R., \& Straub, D. W. (1997). The measurement of the impacts of the IIC on the end-users: The survey. Journal of the American Society for Information Science, 48, 454-465.

Karahanna, E. (1993). Evaluative criteria and user acceptance of enduser information technology: A study of end-user cognitive and normative pre-adoption beliefs. Unpublished doctoral dissertation, University of Minnesota, Minneapolis, MN.

Ronis, D. L., Yates, J. F., \& Kirscht, J. P. (1989). Attitudes, decisions, and habits as determinants of repeated behavior. In: A. R. Pratkanis, S. Brecklar, \& A. G. Greenwald (Eds.), Attitude and structure and function. Hillsdale, NJ: Lawrence Erlbaum. 